\title{
Social and Psychological Features of Entrepreneurs in the Conditions of Behavioural Economy
}

\author{
Rzhevskaya U.E. \\ Departments of the Economic theory and innovatization \\ University of management "TISBI" \\ Kazan, Russia \\ naukatisbi@yandex.ru
}

Kotova O.V.

Department of Financial accounting and taxation University of management "TISBI"

Kazan, Russia

gbrosinter@yandex.ru

\author{
Gryaznov A.N. \\ Department of Pedagogics \\ University of management "TISBI" \\ Kazan, Russia \\ angkazan@rambler.ru
}

\author{
Zabotin A.A. \\ Department of Theory and History of Law of Russia \\ University of management "TISBI" \\ Kazan, Russia \\ zabotinman@gmail.com
}

\begin{abstract}
The economic behavior needs to be controlled, introduced and analyzed. And the main idea here is that it is reasonable. But, nevertheless, "off-screen" there is always a certain share of irrational human behavior. It forms a systematic deviation from rational behavior. And during the creation of business models it is important to consider them. Behavioural economy is the field of economy which studies influence of emotional factors, cognitive and social influences on adoption of economic decisions by people and business and also influence of these decisions on the market. The entrepreneurial economic behavior defines the nature of customer interaction, business partners, competitors, the states and the general details of activity. It includes functions of the market relations, human relations, the impartial persons making decisions and subjects. Within the existing business models of behavior entrepreneurs have an opportunity to maximize own interests and to compete concerning characteristics of the individualized and rational "economists", limited resources, more consecutive.
\end{abstract}

Keywords-entrepreneurs; behavioural economy; social and psychological features; psychological crisis; risks.

\section{INTRODUCTION}

The relevance of this research has no doubts because in society and in economic space there are new risks which has an adverse effect on mentality of entrepreneurs: fear, absence of self- confidence and behavior-confidence. Entrepreneurs find themselves in a difficult life situation which leads to negative social and psychological consequences with no ability to operate by self-mental state. In our case it's failure in business activity because of crisis and change of profession or kind of activity.

All views on function of an entrepreneurship in society are quite fair. Consecutive change of functions contributes to the development of economy, destroys balance, and is a powerful factor of this development as it does not allow economy to stagnate or be imbalanced. These functions are the parts of one coin - the market where the main figure is the entrepreneur.

Each of functions carries out the purpose at the corresponding stage of business development. The first creation of new products on the market. Exactly here entrepreneurial feelings are necessary mainly for information to find potential consumer demand.

The second stage of business activity begins when the consumer demands a new product. This stage is connected with purely organizational issues: production expansion, involvement of new people and so on.

The main task of the entrepreneur is consolidation of all surrounded personnel and direction of his efforts to achievement of the purposes. For this purpose the leader of the company has to have the right to immerse all hired employees in valuable environment which leads to the creation of a certain culture of the organization. At this stage the entrepreneurship represents "social architecture" which studies and creates "standard of work" which are non-material and heavy for the identification of elements which, nevertheless, are extremely important: behavior, values and regulations.

One of the most important features of business activity is that the entrepreneur can act at the same time on different stages for various goods and services. So for a product "A" it can be at the first stage, and for a product "B" it can be already on the third. Nevertheless, each product and service have to pass through all three stages with the entrepreneur. 
Thus, the main function of business activity is the development of social economy by its gradual reduction from a nonequilibrium state to an equilibrium state and vice versa.

\section{LITERATURE REVIEW}

Famous ethic and economic Scottish philosopher Adam Smith ("The theory of moral sense") tried to explain why people make a certain choice in the 18th century, however in the modern world the research of behavioural economy began after creation of the economic theory of a neoclassics based on the principles of economic liberalism and free competition and also studying of behavior of the economic person. (The economic face (homo economus) is any who looks for enrichments and profits, each consumer, the entrepreneur and a hired employee).

In the 20th century model of intertemporal usefulness was expected to be distributed. It led to a creation of a large number of hypotheses of decision making in the conditions of uncertainty, and the choice decision continued eventually. The scientists who found anomalies of selection also became one of learning objects of behavioural economy.

In 1968 the Nobel Prize laureate Gary Becker published article "Crime and punishment: economic approach" in which psychological factors of economic decisions were considered. In 1979 two cognitive psychologists Amos Tverski and Daniel Kahneman published work named "Prospect of the theory: a research of decision making process about risk conditions" in which empirical observations of scientists are generalized.

Since 1980 the theory of game behavior which is also a part of behavioural economy was developed. By the way, in 2002 above-mentioned Daniel Kahneman got the Nobel prize for the integrated data of psychological researches in economic science.

In 2008 one more serious work "Predictably irrational" was published. The author was Dan Arili, professor of behavioural economy. According to popular belief, this book served as a stimulus for the general distribution and promoting of behavior of economy among world audience.

One of the first researchers of an entrepreneurship I.A. Shumpter assumed that he helps society to develop with transition of economy from one equilibrium state to another. In other words, the entrepreneurship has function of destruction of economic equilibrium in society.

\section{RESEARCH METHODOLOGY}

Behavior economy with use of such methods, as experiments, researches on the place, polls, observations, etc. The information required is just obtained by means of experimental modeling (for example, imitation of sales of shares, etc.)

In practice of behavioural economy of a condition as it is possible closer. Often specialists even resort to images of functional magnetic resonance imaging which can define the sites of a brain participating in process of adoption of financial and economic decisions.
In general, the behavioural economy can be divided into three main areas:

Heuristics. The sense is here that people often make decisions, being guided by practical arguments which are not always logically justified. Actually, the mechanics of production is studied.

Market efficiency. In this case the main attention is paid to mistakes in adoption of economic decisions. They can be shown in the irrational made decisions, anomalies in calculation of profit, in establishment of the wrong prices, etc.

Framing. Shot is the semantic structure used for understanding something and the subsequent actions corresponding to this agreement. The design is a formulation of a problem which affects preferences. The effect of creation adheres to the fact that people are sensitive to subtleties of structures. On this basis specialists (experts, politicians, advertisers, etc.). Have an opportunity to affect public opinion, without mentioning or without distorting the facts.

In spite of the fact that the economy is still on the way to development and demands generalized basic theory, in spite of the fact that now it consists of a number of diverse models, scientists could already achieve the results which are important from the practical point of view. They are expressed in private theories, models and paradoxes.

\section{RESULTS}

Social business becomes more and more important part of world economy, and its influence increases every year. Today this area develops under the influence of many factors of instability, including the policy of the government, behavior of investors, global economic conditions, public opinion and the environment. The main question is how it will influence social business next years and what will happen by 2020 . Even the smallest organizations are ready to sign contracts and to provide services on a commercial basis. This trend can have a positive impact and will serve as an opportunity for reconciliation and exchange of positive experience.

There are three types of entrepreneurs: inadvertent management and entrepreneurs romantics. First type was formed among heads of the Soviet companies and without having sufficient resources for this purpose it was placed in conditions of compulsory execution of the planned tasks. Representatives of this type maintained the quality based on updatings of the plan, acquisition of additional resources, concealment of actual resources, increasing of product prices, creation of positions, taking of bribes, etc. Their habits rooted to realize regulation of one law violation - the plan. Objectively the certain "fault" raised a support on the higher authority covering the leader's "sin".

The second is delegated entrepreneur. He began his work in the limited strategic space (important for survival of all system) "with complete freedom of new combinations". Though positive effects are reached quickly, negative consequences for economy, nature and society have long-term or irreversible character. 
Thus, although it is possible to predict significant increase

The third type is moved by self-expression and passion to the intelligent and creative work. It is not just about the rules of management system but it is an involving of new combinations which bypass them or resist them bringing dangers and risks.

\section{DISCUSSION}

It will be difficult to adapt to such changes when small enterprises focus on the local level of work: they will not be able to show considerable social effect which demands large investments, system changes and preparation of a large number of specialists. The closeness to target audience, the best understanding of their requirements and more exact localization of decisions and products will help small enterprises. Various crowdsourcing platforms which in common finance social projects will also bring benefit to small business. In the future they will collect information and will become the Internet platform for some kind of brainstorming to scale and initiate successful cases in a number of the countries and regions.

Behavioural economy is a direction of economic researches. It is significantly important for us that direction contains socially - psychological factors, mental conditions of the entrepreneur identity, influence of social, cognitive, emotional states on economic behavior, adoption of economic decisions by entrepreneurs and consequences of this influence on market changes.

At last, emphasizing the huge practical importance of a problem: check psychosocial characteristics of entrepreneurs to make it possible to hold practical consultations, career guidance and training entrepreneurial capabilities with young entrepreneurs. On the other hand, satisfaction is connected with the entrepreneurial efficiency. Discovering the social and psychological characteristics which connected with the entrepreneurial satisfaction gives the chance to understand factors of social psychology and to increase entrepreneurial efficiency.

\section{CONCLUSIONS}

By 2020 the entrepreneurship in the social sphere will remain in vanguard of social innovations, studying new business models and creating new combinations of resources. The sphere of activity which is most active today can change so that it will be the convenient environment for charity, but the social enterprises move ahead further to solve the most serious problems.

Investors agree to finance such startups and agree that one tenth investments will be successful. Nine unsuccessful projects will be considered only as the following step on the way to success, but not as a shame or the reason for the further termination of investments. Special approach to an entrepreneurship will lead to understanding of the competition and cooperation in this area. For the creation of best model of influence, its testing and wide circulation there are real prerequisites for the beginning to work with business concerns. of an entrepreneurship models popularity in the future, this sector can lose a clear boundary between legal forms and management models, and also features of the activity, concentrating attention on the results.

Psychological description of the entrepreneur includes such features of the personality which distinguish him or her from other people. Foreign and national writers agree with a number of typical aspects of the entrepreneur. He has creative economic activity, risk, order, aspiration to self-realization, resistance to stress, etc. There is a number of the options allowing to mark out characteristics of the domestic entrepreneur in comparison with other country. It is weak social integration, a low estimate of usefulness of his company activity, a low estimate of moral character of the trader of the company and so on.

Therefore, unique characteristics of an entrepreneurship are freedom, responsibility, risk, initiative, comfort for creativity, innovations. The entrepreneurship is considered as activity which structure is defined, main features and functions of society are marked out. It allows to define an entrepreneurship in terms of activity. The entrepreneurship is an innovation activity of people belonging to a certain group of the societies called entrepreneurs with rare capabilities which allow them to bear a burden of unique features of this activity and to develop new skills and economic function for income.

In addition to personal qualities, the entrepreneur has to have a set of knowledge, specific skills in that area in which he or she works. It is obvious that the entrepreneur needs at least a set of knowledge in the sphere of finance, credit and financial accounting and for a person who decides to organize production, for example, of furniture, it is necessary to have minimum technical training for the successful financial transactions. However, these restrictions are not defining. Often it happens that the entrepreneur acquires certain knowledge and skills while running his business and makes decisions on the early stages intuitively or by involvement of experts. The key moment is his desire to study and to improve his skills for the business and this desire belongs to personal characteristics (curiosity, persistence, ambitions).

Discovering the identity of the entrepreneur by means of psychological tests not only helps to clarify some aspects of his personality, but also shows the direction in which he has to work to increase efficiency of the business activity.

\section{References}

[1] Kamneva E.V., Annenkova N.V. Specifics of personal properties of successful entrepreneurs. Scientific Bulletin MGIIT. 2013, 1(21), pp. 6571.

[2] Gabriyelyan E.V., Biron V.M. The prospects of development of small business in modern Russian conditions. the Youth scientific forum: Social and economic sciences: electr. collection on materials of the International Student's Academic and Research Conference. 10(50). URL: https://nauchforum.ru/archive/MNF_social/10(50).pdf

[3] Gadzhiyev A.N., Tutygin A.G., Chizhova L.A. The historical and economic analysis of development of an entrepreneurship in Russia: from S.Y. Witte's reforms till the New Economic Policy period. Synergy of sciences of No1 (December). 2017, pp. 590-602. 
[8] Session 5. Behavioural economy - a key for finding solutions to modern economic problems. Materials of an annual scientific conference the Lomonosov readings. Section of economic sciences "Potential of economic science for development of Russia". Lomonosov Moscow State University. M. 2017.

[9] Strelets I.A. Behaviour of economic agents in the conditions of information cascades. Creative economy. 2014, 12(96), pp. $71-80$.

[10] Alexsandr S. Kuznetsov. Russian Professor's meeting. Russian Journal of Physical Education and Sport. 2019, 14(1), pp. 17-22. DOI: 10.14526/2070-4798-2019-14-1-18-24

[11] Antipina O. N., Nikiforov A. A. Behavioural macroeconomics: on the way to new synthesis? Economy questions. 2016,. 12, pp. 88-103.

7] Nikiforov A. A., Antipina O. N. Behavioural macroeconomic: on the way to new synthesis. Economy Questions. 2016, 12, pp. 88-103. 